\title{
Translation and Validation of the Reduced Western Ontario and Mcmaster Universities Osteoarthritis Index (WOMAC) From English to Yoruba
}

\author{
Ojoawo A.O., Akinwumi O.M. \\ Department of Medical Rehabilitation, College of Health Sciences, Obafemi Awolowo University, Ile Ife \\ Correspondence \\ Dr. Ojoawo Adesola Ojo, Department of Medical Rehabilitation, College of Health Sciences, Obafemi Awolowo \\ University, Ile Ife, Nigeria
}

\begin{abstract}
SUMMARY
The W estern Ontario and McM aster Universities Osteoarthritis Index (W OM AC) developed in English language for assessment of knee osteoarthritis (KOA) may be misinterpreted among Yoruba-speaking patients. This study translated the reduced WOMAC into Yoruba and validated the translated copy with the original one. Sixty radiographically-confirmed knee osteoarthritic subjects in the south-west of Nigeria participated in this study. The original English version of the WOMAC was translated into Yoruba language (used as Yoruba version) by two linguists from the Department of Linguistic and African Languages, Obafemi Awolowo University, Ile-Ife, Nigeria. The Yoruba version was retranslated into English by the English Department of the same university to ensure accuracy. The original and retranslated questionnaires were administered to each subject at 3 days interval. After two weeks the retranslated questionnaire was administered to each subject. The data were analysed using descriptive and inferential statistics.

The results of validation showed that there were positive significant relationships between the scores for the original WOMAC and retranslated WOMAC in all the domains (pain; r=0.996, p<0.001, stiffness; $r=0.971$, $\mathrm{p}<0.001$, difficulty $\mathrm{r}=0.980, \mathrm{p}<0.001)$. The test retest reliability also showed a positive significant relationship (pain; $r=0.996, p<0.001$, stiffness; $r=0.990, p<0.001$, difficulty $r=0.992, p<0.001$ ) between the scores for the retranslated WOMAC at first administration and the scores when re-administered after 2 weeks in all the domains.

It can be concluded from the study that the Yoruba version of the reduced Western Ontario and McMaster Universities (W OM AC) Osteoarthritis Index is reliable and valid as an outcome measure for assessing patients with knee osteoarthritis.
\end{abstract}

KEY WORDS: WOMAC, knee osteoarthritis, pain, stiffness and difficulty

\section{INTRODUCTION}

Globally, osteoarthritis (OA), which can be associated with aging, has a significant impact on disability and morbidity in the elderly. It is a major public health problem (Fransen et al, 2011) with a report of symptomatic knee OA incidence of $10 \%$ in men and $13 \%$ in women aged 60 years or older (Zhang et al, 2010). Research has shown that osteoarthritis of the knee is the second reason for consultation in rheumatology in sub-Saharan Africa and the first location of osteoarthritis in the lower limbs (Ouedraogo, 2014). Ogunlade et al (2005) and Akinpelu et al (2005), in different studies, reported that knee osteoarthritis (KOA) is commonly seen in Nigerian hospitals. Akinpelu et al (2009) reported that one out of every five adults older than 40 years in a Nigerian rural community (Igbo-Ora) had symptomatic knee osteoarthritis 
with a female preponderance and a female to male ratio of $2.1: 1$, that is 2.1 female to 1 male. It is the leading cause of disability affecting $60-70 \%$ of the population older than 60 years. Obesity, work related injuries and injuries due to sports are also some of causes of osteoarthritis (Nguyen et al, 2011).

Osteoarthritis is a degenerative joint disease in which the cartilage covering the ends of bones in the joint breaks down and the bones begin to rub against each other (Arthritis Foundation, 2006). Its major symptoms are pain, poor flexibility and decreased joint range of motion (Onigbinde et al, 2009). Osteoarthritis is the most common form of arthritis with exacerbation of acute inflammation. It affects both male and female but the joint distribution pattern differs according to gender. The prevalence, incidence and severity of osteoarthritis are different in women than in men with women more likely than men to suffer from osteoarthritis and women experience more severe arthritis in the knee. Although presentation of osteoarthritis does not differ between men and women, symptom severity does (O'Connor, 2007).

Most subjects with osteoarthritis usually experience functional limitations in activities of daily living due to joint pain, stiffness, locking, hamstring tightness, regional muscle atrophy and lax ligament (Netter and Freyberg, 1990). The high predilection for the knee joint is largely due to the weight bearing nature of the joint. It is easily susceptible to wear and tear under pressure especially if already in a pathologically deformed state (Moore, 1992).

Outcome measures for clinician researchers in osteoarthritis include:

- Arthritis Impact Measurement Scales - a diseasespecific measure of physical, social, and emotional well-being designed as a measure of outcome in arthritis (Meenan et al, 1999).

- Oxford knee score - used to assess function and pain after total knee replacement (TKR) surgery (arthroplasty) (Murray et al, 2007).

The functional status of patients with knee OA can be assessed either by a battery of tests quantifying physical activity restrictions, such as the 6-minute walk test, the stair climbing test, and the lifting and carrying weight test, or by questionnaires evaluating disability in daily living activities. This last method is relevant and appreciated for its simplicity. Moreover, it allows for assessing the patient's opinion of functional disability. It is increasingly recognized that a key outcome measure for any health-care intervention for OA, as for many other conditions, is a change in healthrelated quality of life (HRQoL) (Liang et al, 1990).

The most widely used condition-specific instruments for the assessment of OA knee and hip is the Western Ontario and McMaster Universities (WOMAC) Osteoarthritis Index (Hawker et al, 1995) which is recommended by the Outcome Measure in Rheumatoid Arthritis Clinical Trial (OMERACT) (Boers et al, 1998). The Western Ontario and McMaster Universities Osteoarthritis Index (WOMAC) is used to assess pain, stiffness, and physical function in patients with hip and/or knee osteoarthritis (OA) (Bellamy 2002). WOMAC is a propriety set of standardized questionnaires used by health professionals to evaluate the condition of patients with osteoarthritis of the knee and hip. It was developed by Western Ontario and McMaster Universities in 1982. WOMAC is available in alternate language forms including: Arabic (Guermazi et al, 2004), Chinese (Xie et al, 2008), Dutch (Roorda et al, 2004), Finnish (Soininen et al, 2008), French-Canadian (Faucher et al, 2002), German (Stucki et al, 1996), Hebrew (Wigler et al, 1999), Italian (Salaffi et al, 2003), Korean (Bae et al, 2001), Moroccan (Falk et al, 2008), Spanish (Escobar et al, 2002), Swedish (Roos et al, 1999), Thai (Kuptniratsaikul and Rattanachaiyanont, 2007) and Turkish (Tunzun et al, 2005).

A few years ago, some redundancies were found in the WOMAC scale and thence it was tapered to give rise to a new version called the reduced WOMAC, which is equally reliable, valid and responsive as the original version (Whitehouse and Lingard, 2003). Though numerous studies are being carried out for linguistic and cross-culture validation of different outcome measures, there have been no previous reports about translation of the reduced WOMAC into Yoruba language. Yoruba is one of the most popularly spoken Nigerian languages and it is the major language of the south-west of Nigeria. The Yoruba are one of the largest ethno-linguistic groups in sub-Saharan Africa. They constitute about 21 percent of the population of modern day Nigeria (Brooks, 2003). For good clinical application of WOMAC within this region, there is a need to have a Yoruba version of WOMAC. Considering the low literacy level in the country, there is the likelihood of misinterpreting WOMAC which was originally in English if it is used for patients who do not understand English. It is therefore necessary to provide Nigerian language (Yoruba) versions of the index. The aim of this study therefore was to translate from English to Yoruba and 
determine the reliability and validity of the Yoruba version of the WOMAC questionnaire.

\section{METHODOLOGY}

Subjects for the study were radiographically-confirmed knee osteoarthritis patients receiving treatment at the Physiotherapy Department of Obafemi Awolowo University Teaching Hospitals Complex, Ile Ife; Ladoke Akintola University of Technology Teaching Hospital, Osogbo and University College Hospital, Ibadan in the south-west of Nigeria. The major inclusive criterion was for the participants to be fluent in both Yoruba and English.

\section{Sampling Determination}

The sample size formula for descriptive study was used:

$$
\begin{array}{ll}
N=\frac{4(\text { Zcrit })^{2} p(1-p)}{D^{2}} & \text { according to Eng (2003) } \\
\mathrm{N} \quad= & \text { sample size of a single study group } \\
\mathrm{Z} \text { crit }= & 1.960 \text { at } 95 \% \text { confidential interval } \\
\mathrm{P} \quad= & \text { a pre-study estimate of proportion to be } \\
& \text { measured which may be assumed to be } 0.80 \\
\mathrm{D} \quad & \text { total width of expected confidential interval } \\
& \quad \text { which is } 0.20 .
\end{array}
$$

The equation yielded 61. Therefore 60 patients were recruited for the study. The purposive sampling technique was used to recruit 60 knee osteoarthritis patients who understand and speak Yoruba and English.

\section{Inclusion Criteria}

Subjects with symptomatic knee osteoarthritis with radiological confirmation and who were fluent in both Yoruba and English were included in the study.

\section{Exclusion Criteria}

Subjects with neurological disorders were excluded and non-Yoruba speaking subjects were excluded.

Research Design: A cross sectional research design was adopted.

\section{Instrumentation}

The main tools used for this study were the reduced WOMAC questionnaire and the translated version of the WOMAC questionnaire. WOMAC consist of 3 sections (A, $\mathrm{B}, \mathrm{C})$ which ask specific questions about hip and knee pain.
Section A asked about the pain felt in the hip/ knee during 48 hours while walking, going up and down stairs, at night, on sitting and during standing up. Section B investigated the severity of stiffness of the hip/knee during sitting during the last 48 hours and section $\mathrm{C}$ assessed the extent of difficulty experienced following physical activities like descending stairs, ascending stairs, rising from sitting and standing. The questionnaire is scored on the 5 Likert scale.

\section{Procedure}

Ethical approval was obtained from the ethical review committee of the Institute of Public Health, Obafemi Awolowo University, Ile-Ife, Osun State, Nigeria. Also, written informed consents were signed by the participants. The guidelines for processing the translation of self-report measures as recommended by Beaton et al (2000) were followed.

Prior to data collection, the original English version of WOMAC was given to two linguists from the Department of Linguistics of Obafemi Awolowo University, Ile Ife, Nigeria, who are proficient in both English and Yoruba and whose mother tongue is Yoruba, for translation into Yoruba. The translated version was used as the Yoruba version. This Yoruba version was then taken to the Department of English Language of the same university for re-translation into English, to ensure accuracy.

Each subject was administered the English or Yoruba version of the WOMAC questionnaire, which was collected immediately. After two weeks, the questionnaires were readministered to each subject for reliability and validity.

\section{Data Analysis}

Data were analysed using SPSS 16 from Chicago Illinois. The results were summarized using descriptive and inferential statistics. Spearman Rho was used to examine the relationship between the original WOMAC score and the Yoruba version score. Also Spearman Rho correlation was used to evaluate the test retest reliability of the Yoruba version of WOMAC. An alpha level of 0.05 was set as level of significance.

\section{RESULT}

The total number of respondents in the survey was 60 . The majority of the participants were female $(75.4 \%)$ compared to the male $(24.6 \%)$. More than two-thirds of the total population $(68.9 \%)$ were married, while $31.1 \%$ were widows and $32.7 \%$ were not educated (see table 1 ). 
The physical characteristics of the respondents are presented in table 2 . The mean age of the respondents was $64.10 \pm 9.56$ years and the mean duration of knee osteoarthritis was $3.80 \pm 1.85$ years with mean difficulty of $28.23 \pm 8.61$.

Table 1. Socio-demographic data of respondents

\begin{tabular}{lcc}
\hline Variables & Frequency & $\%$ \\
\hline Sex & 15 & \\
Male & 45 & 24.6 \\
Female & & 75.4 \\
Marital status & 41 & \\
Married & 19 & 68.9 \\
Widowed & & 31.1 \\
Educational level & 19 & \\
None & 7 & 32.7 \\
Primary & 12 & 11.5 \\
Secondary & 22 & 19.7 \\
Tertiary & & 36.1 \\
\hline
\end{tabular}

Table 2. Physical characteristics of respondents $N=60$

\begin{tabular}{lrrr}
\hline Variables & Minimum & Maximum & \multicolumn{1}{c}{ Mean SD } \\
\hline Age(years) & 40.00 & 80.00 & $64.10 \pm 9.56$ \\
DOA(years) & 1.00 & 5.00 & $3.80 \pm 1.85$ \\
PnTot1 & 2.00 & 18.00 & $8.07 \pm 3.50$ \\
StfTot1 & 0.00 & 8.00 & $4.22 \pm 1.63$ \\
DiffTot1 & 13.00 & 52.00 & $28.23 \pm 8.61$ \\
\hline
\end{tabular}

Keys: DOA- Duration of osteoarthritis; PnTot1- Pain total for original WOMAC score; StfTot1- Stiffness total for original WOMAC score; DiffTot1- Difficulty total for original WOMAC score

Comparison between the male and female original WOMAC scores is shown in table 3. Pain total for male respondents was significantly higher than that of female respondents $(t=3.627, \mathrm{p} 0.001)$ and males had significant more difficulty in carrying out physical activities than females $(\mathrm{t}=2.223, \mathrm{p}<0.05)$.

Table3. Independent t-Test Comparing the mean Original WOMAC Score of Male and Female Respondent

\begin{tabular}{lrrrr}
\hline Variables & $\begin{array}{c}\text { Male } \mathrm{n}=15 \\
\text { Mean } \pm \mathrm{SD}\end{array}$ & $\begin{array}{c}\text { Female } \mathrm{n}=45 \\
\text { Mean } \pm \mathrm{SD}\end{array}$ & t value & $\mathrm{p}$ value \\
\hline PnTot & $10.53 \pm 2.95$ & $7.24 \pm 3.30$ & 3.627 & 0.001 \\
StfTot & $4.53 \pm 1.85$ & $4.11 \pm 1.56$ & 0.796 & 0.435 \\
DiffTot & $3.07 \pm 10.39$ & $26.62 \pm 7.38$ & 2.223 & 0.039 \\
\hline
\end{tabular}

Keys: PnTot- Total pain for WOMAC score; StfTot- Total stiffness for WOMAC score; DiffTot- Total difficulty for WOMAC score

There was a positive relationship $(r=0.996, \mathrm{p} 0.001)$

between total pain of the original WOMAC score and the translated copy, there was also a positive relationship $(r=0.971, p 0.001)$ between total stiffness of the original WOMAC score and the translated copy In addition, there was a positive relationship $(r=0.980, \mathrm{p} 0.001)$ between the scores of the original WOMAC score and the translated copy for total difficulty in physical activity. This is shown in table 4 .

Table 4. Summary of Pearson Moment Correlation Showing Relationship Between the Original WOMAC Score and the Translated WOMAC Score. $\mathrm{n}=60$

\begin{tabular}{lllllll}
\hline Variables & PnTot1 & StfTot1 & DiffTot1 & PnTot2 & StTot2 & DiffTot2 \\
\hline PnTot1 & 1 & & & & & \\
StfTot1 & 0.417 & 1 & & & & \\
DiffTot1 & $0.729 * *$ & $0.541 * *$ & 1 & & & \\
PnTot2 & $\mathbf{0 . 9 9 6 * *}$ & $0.431 * *$ & $0.717 * *$ & 1 & & \\
StfTot2 & $0.404^{* *}$ & $0.971 * *$ & $0.507 * *$ & $0.415^{* *}$ & 1 & \\
DiffTot2 & $0.716^{* *}$ & $0.541 * *$ & $0.980 * *$ & $0.717^{* *}$ & $0.492 * *$ & 1
\end{tabular}

Keys: $* *$ Correlation is significant at the 0.01 level (2 tailed); PnTot1- Pain total for original WOMAC score

StfTot1- Stiffness total for original WOMAC score; DiffTot1- Difficulty total for original WOMAC score

PnTot2- Pain total for first translated WOMAC score; StfTot2- Stiffness total for first translated WOMAC score

DiffTot2- Difficulty total for first translated WOMAC score

\section{Test Retest Reliability of Translated Copy of WOMAC} Presented in table 5 is the relationship between the first scores and the two weeks scores of the translated WOMAC. There was a positive significant relationship $(r=0.996$, $\mathrm{p}<0.001$ ) between the first score for pain intensity of translated WOMAC and the two weeks' score. Also a positive significant relationship $(r=0.990, p<0.001)$ was found between the first score for stiffness and the two weeks' score of the translated WOMAC as well as between the first score and the two weeks' score $(r=0.992$, $\mathrm{p}<0.001$ ) for total difficulty in physical activity of the translated WOMAC.

Table 5. Summary of Pearson Moment Correlation to show relationship between first score of translated WOMAC and two weeks score of translated WOMAC score

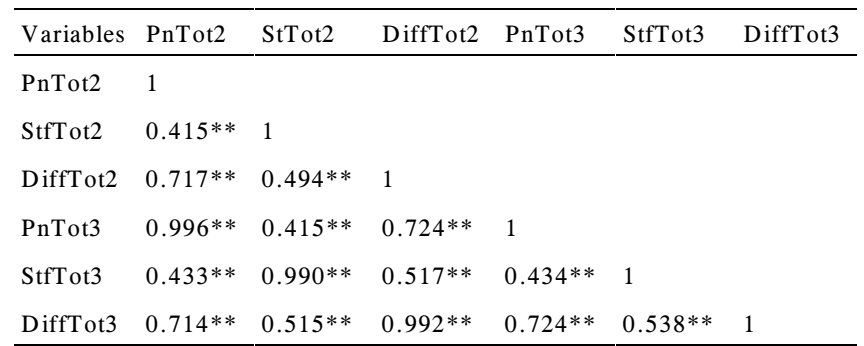

Keys: **Correlation is significant at the 0.01 level (2 tailed); PnTot2- Pain total for first translated WOMAC score; StfTot2- Stiffness total for first translated WOMAC score; DiffTot2- Difficulty total for first translated WOMAC score; PnTot3- Pain total for two weeks score of translated WOMAC, StfTot3- Stiffness total for two weeks score of translated WOMAC; DiffTot3- Difficulty total for two weeks score of translated WOMAC 


\section{DISCUSSION}

It has become increasingly imperative to use outcome measuring tools to assess as well as monitor efficacy and progress in treatment plans designed for different categories of patients. The reduced Western Ontario and McMaster Universities Osteoarthritis Index (WOMAC) is one of the outcome measures utilized as a screening tool for patients with knee osteoarthritis.

The total number of participants in the study was 60 , and there were 15 male and 45 female participants. This shows that the prevalence of osteoarthritis may be higher in females than in males. According to Akinpelu et al (2009), one out of every five adults older than 40 years in a Nigerian rural community (Igbo-Ora) had symptomatic knee osteoarthritis with a female preponderance and a female to male ratio of $2.1: 1$. This was in agreement with the findings of the present study. The results of this study also showed that pain total for men was significantly higher than pain total for female $(t=3.627, p$ 0.001). This showed that men tended to have more severe knee pain than women. This finding was in contrast to the finding of Shalome et al (2011), whose results clearly showed that women have greater pain, more pain sensitivity, and reduced function compared to men.

The results of this study show that there is a positive significant relationship $(r=0.996, p<0.001)$ between the first score and the two weeks score of translated WOMAC for pain. Similarly a positive significant relationship $(r=0.990, p<0.001)$ exists between the first score and the two weeks score of translated WOMAC for stiffness. Also, there is a positive significant relationship $(r=0.992$, $\mathrm{p}<0.001)$ between the first score and the two weeks score of translated WOMAC for physical activity. These findings support a previous report by Jyotsna et al (2010), who developed the Hindu version of WOMAC that is valid and reliable. On the reliability and validity of the Yoruba language, Olaogun et al (2003) found that the Yoruba version for the Verbal Pain Rating Scale was reliable and valid. Similarly, Adedoyin et al (2006) found the Yoruba version of the modified Borg Exhaustion Scale to be reliable and valid for assessing degree of dyspnoea in asthmatic patients. The result of this study also indicated that the Yoruba version of WOMAC is reliable and valid for use in Yoruba-speaking communities.

\section{CONCLUSION}

This study concluded that the Yoruba version of the reduced Western Ontario and McMaster Universities (WOMAC)
Osteoarthritis Index is reliable and valid as an outcome measure for assessing patients with knee osteoarthritis.

\section{RECOMMENDATION}

It is recommended that WOMAC be translated to other Nigeria languages and be validated for effective utilization of the tool in different geopolitical regions of the nation.

\section{References}

Adedoyin R.A., Erhabor G.E., Aikome T.A., Olaogun M.O.B., Johnson O.E., Bisiriyu L.A., Akindele M.O., Akinola T.O. 2006. Validation of Yoruba version of Borg Scale for assessing dyspnea in asthma. Fiyzote Rehab 17(3): 108-112.

Akinpelu A.O., Alonge T.O., Adekanla B.A., Odole A.C. 2009. Prevalence and pattern of symptomatic knee osteoarthritis in Nigeria: A community based study. The Internet Journal of Allied Health Sciences and Practice 7(3).

Akinpelu A.O., Alonge T.O., Adekanla B.A., Odole A.C. 2005. Pattern of osteoarthritis seen in physiotherapy facilities in Ibadan and Lagos, Nigeria. Afri. J. Biomed. Res 10: 111-115.

Ali- Gombe A., Croft P.R., Silman A.Y. 1996. Osteoarthritis of hip and acetabular dysplasia in Nigerian men (abstract). $J$. Rheumatoid 23(3): 512-5.

A r t h r i t i s F u n d a t i o n 20066 . www.arthritisfoundation.com.thefactsaboutarthritis.htm

Bae S. Lee H-S., Yun H.R., Kim T-H., Yoo D-H., Kim S.Y. 2001. Cross-cultural adaptation and validation of Korean Western Ontario and McMaster Universities (WOMAC) and Lequesne osteoarthritis indices for clinical research. Osteoarthritis Cartilage 9: 746-750.

Beaton D.E., Bombardier C., Guillemin F., Ferraz M.B. 2000. Guidelines for the process of cross-cultural adaptation of selfreport measures. Spine 25(24): 3186-91.

Bellamy, N. 2002. WOMAC: A 20-year experiential review of a patient-centered self-reported health status questionnaire. $J$. Rheumatol. 29(12): 2473-6.

Bellamy N., Buchanan W.W., Goldmith C.H., Campbell J., Stitt L. 1988. Validation study of WOMAC: A health status instrument for measuring clinically-important patient relevant outcomes following total hip or knee arthroplasty in osteoarthritis. J Orthop Rheumato 1: 95-108.

Boers M., Brooks P., Strand V.C., Tugwell P. 1998. The OMERACT filter for outcome measures in rheumatology. Editorial. J Rheumatol 25: 198-9.

Boh L.E. Osteoarthritis. In: Di Piro J.T, Talbert R.L, Yee G.C. (Eds) 1999. Pharmacotherapy: A pathophysiological approach $4^{\text {th }}$ ed. Norwalk (CT): Appleton and Lange, pp. 1441-5.

Brooks, George E. 2003. Eurafricans in western Africa: Commerce, social status, gender, and religious observance from the sixteenth to the eighteenth century. Western African Studies. Athens, OH: Ohio University Press.

Eng John. 2003. Sample size estimation: How many individuals should be studied. Radiology 227: 309-313. 
Escobar A., Quintana J.M., Bilbao A., Azkarate J., Guenaga J.I. 2002. Validation of the Spanish version of the WOMAC questionnaire for patients with hip or knee osteoarthritis. ClinRheumatol 21: 466-471.

Falk A., Benbouazza K., Amine B. 2008. Translation and validation of Moroccan Western Ontario and McMaster Universities (WOMAC) Osteoarthritis index in knee osteoarthritis. Rheumatol Int 28: 677-683.

Faucher M., Poiraudeau S., Lefevre-Colau M., Rannou F., Fermanian J., Revel M. 2002. Algo-functional assessment of knee osteoarthritis: comparison of the test-retest reliability and construct validity of the WOMAC and Lequesne indexes. Osteoarthritis Cartilage 10: 602-610.

Fransen M., Bridget L., March L., Hoy D., Penserga E., Brooks P. 2011. The epidemiology of osteoarthritis in Asia. Int $J$ Rheum Dis 14(2):113-21.

Guermazi M., Poiraudeau S., Yahia M. 2004. Translation, adaptation, and validation of the Western Ontario and McMaster Universities osteoarthritis index (WOMAC) for an Arab population: The Sfax modified WOMAC. Osteoarthritis Cartilage 12: 459-468.

Hawker G., Melfi C., Paul J., Green R., Bombardier C. 1995. Comparison of a generic (SF-36) and a disease specific (WOMAC) instrument in the measurement of outcomes after knee replacement surgery. J Rheumatol 22: 1193-1196.

Jyotsna Sharma, Khan Sohrab A., Rustgi Saroj. 2010. Translation and validation of the reduced Western Ontario and McMaster Universities Osteoarthritis index (WOMAC) in Hindi speaking Indian patient with osteoarthritis of knee. Indian Journal of Physiotherapy and Occupational Therapy 4(4): 37-41.

Kuptniratsaikul V., Rattanachaiyanont M. 2007. Validation of a modified Thai version of the Western Ontario and McMaster (WOMAC) osteoarthritis index for knee osteoarthritis. ClinRheumatol 26: 1641-1645.

Liang M.H., Fossel A.H., Larson M.G. 1990. Comparisons of five health status instruments for orthopedic evaluation. Med Care 28: 632-42.

Meenan R.F., Callahan L.F., Helmick C.G. 1999. The National Arthritis Action Plan: A public health strategy for a looming epidemic. Editorial. Arthritis Care Res 12: 79-81.

Moore K.L. 1992. Lower Limbs, Clinically Oriented Anatomy $3^{\text {rd }}$ edition. Baltimore: William and Wilkins; pp.421-423.

Murray D.W., Fitzpatrick R., Rogers K., Pandit H., Beard D, Carr A.J,, Dawson J. 2007. The use of the Oxford hip and knee scores. J Bone Joint Surg (BR); 89-B: 1010-14.

Netter F.H., Freyberg R. 1990. Rheumatics diseases. In: Nelder FH, ed. The Gba Collection of Medical Illustrations. Gmmit SFA: Ciba-Gegy Corporation,:178-181.

Nguyen U-S. D. T., Zhang Y., Zhu Y., Niu J., Zhang B., Aliabadi P., Felson DT. 2011. Increasing prevalence of knee pain and symptomatic knee osteoarthritis. Annals of Internal Medicine 155(11): 725-732.

O'Connor, Mary I. 2007. Sex difference in osteoarthritis of the hip and knee. Journal of the American Academy of Orthopaedic Surgeons 15. S22-S25.
Ogunlade S.O., Alonge T.O., Omololu A.B., Adekolujo O.S. 2005. Clinical spectrum of large joint osteoarthritis Ibadan, Nigeria. European Journal of Scientific Research 11: 116 122.

Olaogun M., Adedoyin R.A., Anitaloba R.O. 2003. Reliability and concurrent validity of the Visual Analogue Scale and modified Verbal Rating Scale of pain assessment in adult patients with knee osteoarthritis in Nigeria. South Africa Journal of Physiotherapy 59(2): 12-15.

Onigbinde A.T., Adetogun G.E., Ojoawo A.O., Omotuyi O.C. 2009. Comparative efficiency of low metal glucosamine sulphate-iontophoresis in the management of lumbar spondylosis. India Journal of Physiotherapy and Occupational Therapy 13(3).

Ouedraogo D.D, Ntsiba, H., Tiendrébéogo Zabsonré, J., Tieno, H., Bokossa, L.I.F., Kaboré, F. and Drabo, J. 2014. Clinical spectrum of rheumatologic diseases in a department of rheumatology in Ouagadougou (Burkina Faso). Clinical Rheumatology 33: 385-389.

Roorda L.D., Jones C.A., Waltz M. 2004. Satisfactory cross cultural equivalence of Dutch WOMAC in patients with hip osteoarthritis waiting for arthroplasty. Ann Rheum Dis 63: 3642.

Roos E.M., Klassbo M., Lohmander L.S. 1999. WOMAC osteoarthritis index. Reliability, validity, and responsiveness in patients with arthroscopically assessed osteoarthritis. Western Ontario and MacMaster Universities. Scand $J$ Rheumatol 28: 210-5.

Salaffi F., Leardini G., Canesi B. 2003. Reliability and validity of the Western Ontario and McMaster Universities (WOMAC) Osteoarthritis Index in Italian patients with osteoarthritis. Cartilage 11: 551-560.

Shalome M.T., Barbara A.R., Nicholas A.C., Whitney L.A., Kathleen A.S. 2011. Women with knee osteoarthritis have more pain and poorer function than men, but similar physical activity prior to knee replacement. Biology of Sex Differences 2(12). doi:10.1186/2042-6410-2-12.

Soininen J.V., Paavolainen P.O., Gronblad M.A., Kaapa E.H. 2008. Validation study of a Finnish version of the Western Ontario and McMasters University Osteoarthritis Index. Hip International 18(2): 108-111.

Stucki G, Stucki S, Michel BA, Tyndall AG, Dick W, Theiler R. 1996. Evaluation of a German version of WOMAC (Western Ontario and McMasters Universities) Arthrosis index. $Z$. Rheumatol. 55: 40-49.

Tonelli S.M., Rakel B.A., Cooper N.A., Angstom W.L., Sluka K.A. 2011. Women with knee osteoarthritis have more pain and poorer function than men, but similar physical activity prior to total knee replacement. Biology of Sex Differences 2: 12. http://doi.org/10.1186/2042-6410-2-12.

Tunzun E.H., Eker L., Aytar A., Daskapan A., Bayramoglu M. 2005. Acceptability, reliability, validity and responsiveness of the Turkish version of WOMAC osteoarthritis index. Osteoarthritis Cartilage 13: 28-33. 
Whitehouse S.L., Lingard E.A., Katz J.N., Learmonth I.D. 2003. Development and testing of a reduced WOMAC function scale. J Bone Joint Surg Br 85(5): 706-11.

Wigler I., Neumann L., Yaron M. 1999. Validation study of a Hebrew version of WOMAC in patients with osteoarthritis of the knee. ClinRheumatol.18: 402-405.

Xie F., Li S.C., Goeree R. 2008. Validation of Chinese Western
Ontario and McMaster Universities Osteoarthritis Index (WOMAC) in patients scheduled for total knee replacement. Qual Life Res.17: 595-601.

Zhang W., Doherty M., Peat G. 2010. EULAR evidence-based recommendations for the diagnosis of knee osteoarthritis. Ann. Rheum. Dis. 69: 483-9. 